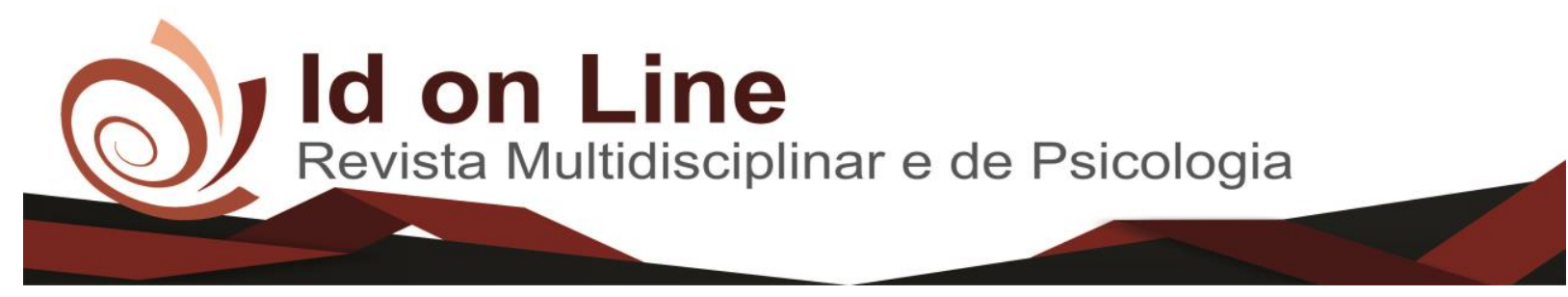

Comment

\title{
A Música como atividade interativa no desenvolvimento crítico e social da Educação Infantil
}

\author{
Maria Matilde de Barros Pereira ${ }^{1}$
}

\begin{abstract}
Resumo: Este estudo aborda a música como meio lúdico na educação infantil, interagindo entre a escola e o aluno, facilitando o aprendizado e o desenvolvimento psicosocial por meio do lúdico, o que vai contribuir para a atividade educativa do dia a dia da criança; a música é uma linguagem que se traduz em formas sonoras capazes de expressar e comunicar sensações, sentimentos e pensamentos, estando presente em todas as culturas e fazendo parte da educação desde os tempos remotos, sendo considerada como fundamental para a formação dos cidadãos, por ser uma arte com capacidade de fazer pensar e educar. É uma das formas importantes no contexto da educação, especialmente na educação infantil, pela facilidade que ela proporciona à aprendizagem. Percebeu-se, através dessa pesquisa, que houve grande evolução na compreensão do ensino educacional e psicosocial, quando se utiliza a música de forma simples e prazerosa, beneficiando o educando e facilitando o trabalho docente em sala de aula.
\end{abstract}

Palavras chave: Música. Linguagem. Educação infantil.

\section{Music as an interactive activity in the critical and social development of Early Childhood Education}

\begin{abstract}
This study addresses the music as kind of playful on early childhood education, interacting between the school and the student, facilitating learning and psychosocial development by means of the playful, which will contribute to the educational activity of the day-to-day; music is a language that translates into sound shapes able to express and communicate sensations, feelings and thoughts, being present in all cultures and part of education since ancient times, being considered as fundamental to the formation of citizens, for being an art capable of make you think and educate. Is one of the important ways in the context of education, especially in early childhood education, the facility that it provides to learning. It was realized, through this research, that there have been great developments in the understanding of educational and psychosocial education, when using the music in a simple and enjoyable, benefiting the educating and facilitating the teaching work in the classroom.
\end{abstract}

Keywords: Music. Language. Early childhood education.

\section{Introdução}

Esta pesquisa aborda a utilização da música em sala de aula, objetivando oferecer ludicamente um melhor desenvolvimento educacional, abordando também, a realização de um trabalho valoroso com a música desde a antiguidade até os dias atuais.

${ }^{1}$ Graduando em Licenciatura Plena - Pedagogia/2017-2 - pela Faculdade de Ciências Humanas do Sertão Central - FACHUSC, Tel.87-38710217 - e-mail: mariamatildebarros120@gmail.com 
Contribui muito com a educação e desenvolvimento psicosocial, acompanhando a história da humanidade em muitas culturas. Este estudo tem por objetivo geral, compreender a utilização da música como meio lúdico para a aprendizagem e desenvolvimento psicosocial infantil.

Diante do objetivo geral surgem os objetivos específicos, que são: entender a história da música em diferentes culturas humanas; verificar o ensino educacional com a utilização da música como meio lúdico interagindo no desenvolvimento da criança em sala de aula; analisar como os instrumentos musicais serão construídos pelos alunos, com o auxilio do professor; e, observar os espaços para realização das atividades musicais educativas.

Diante dos objetivos surge à problemática: como acontece a aprendizagem por meio da música na educação infantil? Sabendo que o ser humano está envolvido com a cultura musical desde muito cedo, ou seja, do ventre da mãe, a música é um processo contínuo de novas construções envolvendo vários sentidos do ser humanos como: alegria, tristeza e sonho.

A justificativa deste estudo parte do fato de que a Música é uma linguagem muito importante; um meio de expressar sentimentos e idéias dos mais variados e está presente em muitos momentos da nossa vida, tais como: comemorações, festividades em geral, rituais religiosos, velórios e similares.

Essa temática contextualiza a música como atividade interativa no desenvolvimento infantil crítico-social, pois a música está praticamente em tudo na vida; irá contribuir para a formação de seres humanos em sociedade, criativos e construtivos. Como metodologia, foi utilizada pesquisa bibliográfica, tendo como suporte teórico as autoras: Alicia Maria Almeida Loureiro (2010), Bernadete Zagonel (2012), Teca Alencar de Brito (2013), entre outros.

As atividades lúdicas são indispensáveis à prática educativa, acredita-se que através da ludicidade, a criança constrói e reconstrói os seus conceitos e conhecimentos de maneira natural; a noção do conhecimento musical surge da ação da criança com o lúdico e, daí uma ligação com os demais saberes.

Esta pesquisa se organiza em tópicos: primeiro veremos a música, com valores e concepções, mostrando a história da música em várias culturas humanas até chegar ao Brasil e como ela era utilizada. Em seguida, teremos música no desenvolvimento educacional da criança, com a linguagem musical no espaço infantil facilitando a aprendizagem em vários 
momentos como, brincadeiras de rodas, no fazer instrumentos ou músicas; tais atividades despertam, estimulam e desenvolvem gosto musical.

Logo após, apontamos o uso da música como meio auxiliar na educação infantil com brincadeiras lúdicas criando um ambiente significativo e atraente, servindo como estímulo integral do educando, interagindo com os colegas e professor; com isso estabelece laços de amizade e respeito ao outro; é uma preparação para o crescimento do individuo.

Também o professor deve organizar um espaço aconchegante para as cantigas de roda; para as brincadeiras que se movimentam bastante e para confecção dos instrumentos, com mais liberdade no momento das atividades, seja na sala de aula, na biblioteca, no pátio ou outro local disponível, devendo dispor de espaços agradáveis e confortáveis, facilitando mais ao docente e discente, na realização de suas atividades diárias.

Por fim, a relação entre a música, construção de seus instrumentos, planejamento e ação docente, instrumentos construídos pelas próprias crianças, o que interage com suas criatividades e os impulsionam na busca do saber mais sobre outras coisas que estão sendo transmitidas pelo educador sugeridas através da música, tornando-se imperioso que o professor valorize e respeite os instrumentos e seus alunos do jeito que eles são, independentemente de cor, raça ou com necessidades especiais. Essas atividades de confecções propondo que as crianças toquem, conheçam e explorem aumenta o interesse e a criatividade do educando.

Também é importante que o professor realize atividade de criar e executar a música com os alunos, auxiliando no que for necessário, mas deixando a criança livre expondo suas idéias ao produzir suas próprias músicas.

Também é importante que o professor realize atividade de criar e executar a música com os alunos, auxiliando no que for necessário, mas deixando a criança livre, podendo expor suas idéias ao produzir suas próprias músicas, pois é nesse momento de improviso que ela está criando, compondo e interpretando com grande alegria, emoção e desenvolvimento.

Com a elaboração deste trabalho espera-se que o estudo seja produtivo e valoroso para os demais educadores e pesquisadores, incluindo-o em seu planejamento para por em prática com o intuito de facilitar a aprendizagem das crianças por meio da música, por ser realmente um fator lúdico contribuinte no aprendizado e desenvolvimento psicosocial. 


\section{Músicas, Valores e Concepções}

Existem várias maneiras de interpretar e entender a música dependendo de cada época e cultura humana, seu modo de pensar, agir e seus valores conceptivos.

Nas civilizações antigas os gregos se identificaram com a música fazendo com que ela tornasse uma disciplina ou, uma arte capaz de fazer pensar e educar, a palavra música tem origem grega que significa a arte das musas; uma forma de arte que consiste em combinar vários sons e ritmos, o que já faz parte integrante da nossa vida, estando presente à nossa volta desde os tempos remotos, pois segundo Zagonel "a história mostra que o ser humano sempre sentiu necessidade de documentar e, de alguma forma, eternizar suas criações artísticas para que elas pudessem ser reproduzidas e apreciadas por muitos em qualquer tempo." (ZAGONEL, 2012, p. 21), desta forma observa-se que o homem cria suas artes para expor eterna e historicamente, ainda que esta não seja divulgada amplamente.

Através da música e seus elementos o homem se inspira cria e registra fatos importantíssimos de sua vida para que sejam históricos e vistos por todos, diz Marta:

[...] o objetivo da educação musical é levar a criança a construir conhecimento musical, interagir com a linguagem musical, bem como com os elementos que a formam: ritmo melodia, timbre, dinâmica e forma, por meio de atividades musicais que proporcionem manipulação direta com tais elementos como a apreciação musical, a execução e a criação: (MARTA DECKERT, 2012, p. 15).

A educação na Grécia não era passada apenas através dos livros, mas nas experiências vivida de cada ser humano através da música.

A música foi ganhando espaço e passando a ser vista como ensino do canto nas igrejas católicas louvando a paixão religiosa, o canto ordenou-se do papa Gregório Magno, esses cantos litúrgicos passavam a palavra de Deus, mesmo com as canções emitidas em uma só voz e melódicas, simbolizavam a fé em Cristo. Comenta Loureiro que:

Gregório Magno, papa de 590 a 604, deu ordenação definitiva ao rito, portanto, ao canto litúrgico. Elaborou dois livros, intitulados antiphonarium e cantatorium, que continha os melhores cantos e os novos hinos, segundo a ordem das festas e cerimônias e, que deveriam servir de norma a toda igreja católica (LOUREIRO, 2010, p. 38).

Os protestantes também usavam a música nos cultos, por isso houve a disputa por fiéis entre a igreja católica e a protestante, com essa divisão chamada de reforma protestante acabou dando nome e força a igreja liderada por Martinho Lutero, que usava a música para seu 
desenvolvimento, Loureiro afirma que "graças à influência dos protestantes e dos católicos, sobretudo dos jesuítas, a educação musical nas escolas até o final do século XVIII foi praticada com fins estritamente religiosos." (LOUREIRO, 2010, p. 41). Assim, se verifica que com essas disputas religiosas, a música foi ganhando espaço, sendo usada nas escolas como uma educação religiosa.

O ensino da música ganhou modernização no Brasil com a mistura dos europeus, africanos e indígenas, iniciando com a vinda dos jesuítas que elegeram a educação como uma arma para defender a igreja católica das lutas religiosas que surgiram na Europa. Os nativos que aqui já residiam, usavam grande variedade de práticas musicais; como disse Loureiro, "Eram eles, músicos natos que, em harmonia com a natureza, cantavam e dançavam em louvor aos deuses, durante a caça e a pesca, em comemoração ao nascimento, casamento, morte, ou festejando vitórias alcançadas.” (LOUREIRO, 2010, p. 43).

Acredita-se que a música tenha surgido há 50.000 anos quando a raça humana expandiu pelo planeta e as primeiras manifestações históricas foram feitas no continente africano que eram dos padres jesuítas que se apropriaram das manifestações artísticas para comunicar sua mensagem de fé e buscavam aproximação com os povos nativos.

Os padres jesuítas tiverem uma forte ligação com os indígenas por meios da música que os jesuítas usavam para catequizar, com todos esses esforços de cantos e apresentação de instrumentos pelos jesuítas não havia prática educativa todo esse processo era somente religioso para atrair a atenção dos indígenas. Brito esclarece que "A criação de instrumentos musicais meios para a expressão sonora - seguiu uma trajetória coerente, adequada às necessidades e possibilidades de cada povo, em cada época e lugar." (BRITO, 2013, p. 69).

Chegando ao Brasil como escravos, os africanos trouxeram, instrumentos como o ganzá, a cuíca e o atabaque; então dançavam e cantavam aos sons e ritmos da sua terra natal, graças aos escravos por criarem músicas e instrumentos enriquecendo a música brasileira, conforme entendeu Brito, ao afirmar que:

\footnotetext{
Por isso, tão importante quanto conhecer e preservar nossas tradições musicais são conhecer a produção musical de outros povos e culturas e, de igual modo, explorar, criar e ampliar os caminhos e os recursos para o fazer musical. Como uma das formas de representação simbólica do mundo, a música em sua diversidade e riqueza, permite-nos conhecer melhor a nós mesmos e ao outro - próximo ou distante. (Brito, 2013, p. 28).
}

Com o fim da escravidão e a vinda dos imigrantes europeus para o trabalho na agricultura trouxeram diversos ritmos, um deles a mazurca que acaba virando um movimento rítmico 
brasileiro e, com o tempo, foi se transformando em "maxixe", uma das danças de rua, sendo que a música popular brasileira só se daria com o samba urbano, o carnaval, um dos ritmos mais famosos do Brasil que na visão de Deckert, “Todos esses exemplos mostram que o ritmo não é um elemento presente apenas na música, ele faz parte da nossa vida.” (DECKERT, 2012, p. $31)$.

Sabe-se que na cultura popular brasileira, principalmente na música infantil, encontrase muita riqueza de materiais e produtos musicais que se pode trazer para o ambiente de trabalho infantil em sala de aula. Com as novas tecnologias que vem surgindo, à música popular vem aumento cada vez mais nos rádios, televisão e em várias outras mídias, desta forma, Brito recomenda que "A música da cultura popular brasileira e, por vez, de outros países deve estar presente.” (BRITO, 2013, p. 94).

No decorrer do tempo a nossa educação infantil brasileira vem atendendo a propósitos diversos no dia a dia para formação de hábitos e atitudes educativas e psicosociais da criança.

\section{Músicas no desenvolvimento educacional da criança}

A música está presente na nossa vida desde o ventre da mãe até o fim da vida; é uma linguagem sonora capaz de expressar sentimentos, pensamentos e nos acompanha em muitos momentos, como: festividade em geral, rituais religiosos, velórios e similares. A linguagem musical é uma das formas importantes de expressão humana, presentes no contato da educação em geral, mas principalmente na educação infantil onde as crianças ficam encantadas com a música, proporcionando seu aprendizado através do lúdico, como relata Queiroz, ao dizer que "A música é uma importante forma de expressão humana, repleta de alegrias, tristezas, sonhos, desilusões e utopias, que permitem as crianças mergulharem no mundo dos sonhos, da fantasia e da realidade.” (QUEIROZ, 2011, p. 23).

As crianças entram em contato com a cultura musical desde muito cedo e assim começam a aprender suas tradições musicais. Essa linguagem no espaço infantil vem atendendo a vários momentos que viram rotina, como no horário de lavar as mãos antes do lanche, ir para o lanche, nas brincadeiras de rodas, na hora do recreio, ouvir e aprender uma música, brincar de roda com canções que costumam ser acompanhadas por gestos corporais; são algumas formas que despertam, estimulam e desenvolvem o gosto pela atividade musical. 
O trabalho com música é excelente meio para o desenvolvimento da auto-estima, integração social e da expressão da criança com os coleguinhas e o meio que o cercam; neste contexto discorre Fraidenraich "é dessa forma que a criança começa a compreender algumas regras de convívio e os papéis sociais.” (FRAIDENRAICH, 2012, p. 27). São nos primeiros contatos que a criança tem com a música, importantíssimos para sua aprendizagem em todos os sentidos, pois aumenta sua sensibilidade e prazerosamente descobre o mundo a sua volta.

A música na educação pode envolver vários componentes curriculares facilitando seu conhecimento: a exemplo da matemática, quando marcamos um ritmo, se quer saber a quantidade que se deve tocar, sendo várias letras de músicas que ajuda e facilita a aprendizagem de números, quantidade e classificação; na língua portuguesa, no momento que se brinca com a caixinha de surpresa usa-se a música, quando a mesma para, a criança identifica a letrinha ou imagem que está dentro e aí começa a cantar representando as imagens; assim, verifica-se que a música é um fator contribuinte das aprendizagem no ambiente escolar, principalmente infantil, por ser facilmente induzido ao aprendizado lúdico.

\section{O uso da música como meio auxiliar na educação infantil}

Na educação infantil o uso da música por meio das brincadeiras lúdicas cria um ambiente significativo e atraente, servindo como estímulo para o desenvolvimento integral do educando. A atividade lúdica é indispensável à prática educativa, pois a noção do conhecimento da criança surge com o lúdico, o qual pode ser proporcionado com a música.

As brincadeiras musicais auxiliam no desenvolvimento das crianças em diferentes vivências ou conhecimentos, dependendo da intencionalidade educativa, de ensino e aprendizagem e das variadas que se encontra no planejamento do professor; com o lúdico a criança irá socializar seus brinquedos instrumentais, interagindo com os colegas e professores, estabelecendo laços de amizade e respeito ao outro; é uma preparação para a vida em sociedade; assim se manifesta Fraidenraich.

De fato, a brincadeira proporciona diversos benefícios nessa faixa etária, estimulando capacidades como atenção, a memória e a imaginação. Permite, também, amadurecer no relacionamento social por meio do contato com os colegas e adultos que não são do circulo familiar. (Revista Gestão Escolar. apud Verônica Fraidenraich, 2012, p. 27). 
Considerando o lúdico como um instrumento importantíssimo para o desenvolvimento integral da criança deixando a aprendizagem mais interessante e significativa, pois as brincadeiras fazem parte do mundo de todas as crianças, cabe salientar que cada atividade favorece o processo de aprendizagem da criança à medida que oferece a ela, os jogos, dança, bandinha rítmica, brincadeiras de rodas e outros, dando a oportunidade de expressar suas emoções e construir significados para cada nova vivência adquirida; as crianças aprendem através do contato, tocando os objetos, vendo, sentindo, ou seja, experimentando sensações e movimentos, patrocinados pela música estimulando seus impulsos.

O brincar favorece a auto-estima dos alunos, pois a brincadeira faz com que a criança adquira mais confiança e, isso faz a diferença na aprendizagem, pois quando a criança está brincando, ela fica com o pensamento distante da vida cotidiana, entrando no mundo imaginário e ilusório; ela não se preocupa com a aquisição de conhecimento ou desenvolvimento de qualquer habilidade física ou mental, porém, ela fica com o pensamento em outro lugar no mundo da imaginação, de onde surge a criatividade.

O professor deve organizar um espaço aconchegante para as cantigas de roda, brincadeiras e jogos que se movimenta bastante, assim como as atividades de confecção de instrumentos e outros; sabendo-se que o espaço escolar não é só o da sala de aula, mas os arredores, como pátio, auditório e biblioteca, os quais podem ser usados dependendo da organização, facilitando a prática educativa, tanto para o aluno quanto para o professor que, para execução de seu trabalho com eficiência e rapidez, é imperativo que visualize todos os alunos, para um pronto atendimento e sucesso no aprendizado, razão pela qual, os espaços precisam ser agradáveis e confortáveis a todos, conforme discorre Fraidenraich ao comentar que [...] "Por isso, é importante ter intencionalidade no uso de cada espaço e material pedagógico, para tornar enriquecedoras as experiências e vivências dos pequenos" (FRAIDENRAICH, 2012, p. 27). Assim, o professor deve aproveitar cada lugar da escola, com atividades significativas e materiais adequados, para que o educando aproveite seu potencial nas atividades desencadeadas visando um melhor aproveitamento educativo.

\section{Relações entre música, construção de instrumentos, planejamento e ação docente}

É de suma importância a atividade de construção de instrumentos musicais pelas próprias crianças; para tal é importante que o professor valorize e respeite os instrumentos e seus alunos, 
estes, do jeito que eles são, independentemente de cor, raça ou com necessidades especiais. Para isso é preciso que o professor seja observador, tenha olhar atento e, sensibilidade para perceber as necessidades de seus alunos, estimulando-os a não pararem de estudar; além de buscar sempre novos conhecimentos e ser sempre inovador, melhorando sua aprendizagem, sua qualidade de vida e também de seus educandos.

Essas atividades de confecção de instrumentos musicais propondo que as crianças as desenvolvam, conheçam e explorem, aumentam o interesse e a criatividade do educando, além de contribuir para a produção de som e suas qualidades, desenvolvendo a imaginação e a criatividade da criança, conforme ensinam Mateiro, Ilari quando dizem que "o papel da música nas escolas não é o de formar instrumentistas, mas o de proporcionar o contato com a música através de experiências variadas e criativas” (MATEIRO; ILARI, 2011, p. 251).

O educador deve dar oportunidade à criança de viver a música e seus ritmos apreciando, cantando, movimentando e criando-os, assim contribui para novas aprendizagens, como ainda enfatizaram Mateiro e Ilari, ao declararem que [...] "A criança deve estar constantemente sendo convidada a criar e improvisar por meio da voz, do corpo e dos instrumentos, de modo a expressar-se musicalmente e comunicar-se através da música" (MATEIRO; ILARI, 2011 p. 308).

O papel do professor é de grande importância nesse processo, deixando a criança livre para manusear e experimentar os materiais, como também observarem os acontecimentos indicando aos infantes, os problemas reais a serem resolvidos; na construção de instrumentos, a criança tem a oportunidade de novas idéias ao trabalhar em equipe, criando, imitando, pesquisando de várias maneiras e imaginando o que pode ser feito, com tudo o esclarecimento de como o som e seus elementos são produzidos, na visão Mateiro e Ilari, “A criança participa da criação a manutenção do instrumento, o que pode ser muito útil quando ela própria tiver de cuidar de um instrumento de verdade” (MATEIRO; ILARI, 2011, p. 208 ).

Para confecção de instrumentos como "tamborzinho", "pandeirinho", "pauzinho" entre outros, pode ser utilizado sucatas e materiais recicláveis desde que estejam limpos, uma vez que atividades com variados instrumentos são de grande riqueza no desenvolvimento infantil.

O primeiro contato com os instrumentos musicais causa na criança muita curiosidade ao saber que, além de sua voz, existem diversos instrumentos para tocar e criar músicas, despertando o interesse em pegar e tocar, como se fosse um brinquedo; na educação infantil o educador deve trabalhar de forma lúdica na aprendizagem e no desenvolvimento da criança. É importante que o professor realize atividade de compor a música com os alunos, 
auxiliando no que for necessário deixando a criança livre e podendo expor suas idéias ao produzir suas próprias músicas, pois naquele momento ela está improvisando, compondo e interpretando com grande alegria e emoção, ao que Mateiro e Ilari se reportam assim; "O prazer e a alegria de fazer a música devem ser ressaltados, contribuindo, assim, para o desenvolvimento emocional da criança" (MATEIR;, ILARI, 2011, p. 309).

Ao realizar estas atividades, a criança se sente integrante, participativa, criativa e com facilidade para se expressar e comunicar-se com a sociedade, o que é um ótimo estímulo para a aprendizagem em diversas áreas, segundo explica Zagonel abaixo:

A criação musical deve ser o ponto central do processo de ensino-aprendizagem ou de prática musical. Mais do que o aprendizado ou a execução perfeita de exercícios e músicas, o importante é propiciar, por meio da musicalização, modificações internas que levem ao crescimento do individuo. (Zagonel, 2012, p. 17).

Ao criar uma música a criança está preparada para fazer outras coisas com o passar do tempo, tornando-se um ser humano melhor preparado, sem medo de agir diante das dificuldades encontradas na sociedade em que está inserida.

\section{Considerações finais}

Esta pesquisa abordou a importância da música como instrumento de suma valia na vida das pessoas e sua educação, principalmente na aprendizagem da educação infantil, onde serve como meio auxiliar de ensino, proporcionando a forma lúdica que facilita a coordenação motora, o desenvolvimento psicosocial e o aprendizado como um todo; teve como objetivo geral "compreender a utilização da música como meio lúdico para a aprendizagem e desenvolvimento psicosocial infantil", aonde se chegou à conclusão de que a música vem acompanhando a história da humanidade em muitas culturas e desde muito cedo está intimamente ligada às pessoas, desde o ventre da mãe, sendo indispensável à sua evolução.

Sabendo-se que o ser humano está envolvido com a cultura musical desde muito cedo, procurou-se desenvolver a pesquisa visando esclarecer os objetivos específicos que são: entender a história da música em diferentes culturas humanas; verificar o ensino educacional com a utilização da música como meio lúdico interagindo no desenvolvimento da criança em sala de aula; analisar como os instrumentos musicais serão construídos pelos alunos, com o auxilio do professor; e, observar os espaços para realização das atividades musicais educativas; 
percebeu-se que a linguagem musical é uma das formas importantes de expressão humana e está presente no contato da educação em geral, mas principalmente na educação infantil, onde as crianças ficam encantadas, tendo a música como uma aliada componente condutora no processo contínuo de novas construções e que envolve vários sentimentos do ser humano, tais como: alegria, tristeza e sonhos, entre outros.

Quanto à problemática questionando: “como acontece à aprendizagem por meio da música na educação infantil?” Esclareceu-se que a música como atividade interativa no desenvolvimento crítico e social na educação infantil, é possível com a construção de instrumentos musicais, a composição e execução das músicas, aliadas as brincadeiras de rodas como atividades facilitadoras que contribuem para a aprendizagem e o desenvolvimento do educando, onde o professor planeja e desencadeia as atividades com ampla visão dos locais préestabelecidos, orientando os discentes sem interferir em suas criatividades, utilizando a música como meio auxiliar de ensino, como estimulo lúdico.

Vale lembrar que a atividade lúdica é indispensável à prática educativa, pois é através da ludicidade que a criança constrói e reconstrói os seus conceitos e conhecimentos de maneira natural, onde a noção do conhecimento é facilitada através do lúdico que pode surgir também da ação da criança interagindo com a música em suas várias atividades na vida.

É necessário que nós acadêmicos e educadores venhamos praticarmos e construir em nosso planejamento diante das necessidades das crianças, uma forma que despertemos seu interesse para a aprendizagem de uma forma tão simples e prazerosa encontrou a música um fator lúdico contribuinte, assim levando o educando a ser um cidadão critico e social.

\section{Referências}

BRITO, Teca Alencar de - Música na educação infantil: Teca Alencar de Brito; (propostas para a formação integral da criança). - $7^{\mathrm{a}}$ Ed. Petrópolis-RJ, 2013.

DECKERT, Marta - Educação musical: da teoria à prática na sala de aula: Marta Deckert - $1^{\text {a }}$ Ed. - São Paulo: Moderna, 2012. (cotidiano escolar: ação docente).

FRAIDENRAICH, Verônica - educação infantil, o que é importante para garantir a qualidade do atendimento na creche e na pré-escola. - (revista gestão escolar), 2012. 
LOUREIRO, Alicia Maria Almeida - $O$ ensino de música na escola fundamental: Alicia Maria Almeida Loureiro. - Campinas, SP: Papirus, $7^{\text {a }}$ Ed. 2010. - (coleção Papirus educação).

MATEIRO, Teresa - Pedagogias em educação musical/Teresa Mateiro, Beatriz Ilari, (org.) Curitiba: Ibpex, 2011. - (série educação musical).

QUEIROZ, Tânia D. - Manual pedagógico: do educador da educação infantil e dos anos iniciais do ensino fundamental. rideel editora, São Paulo: 2011.

ZAGONEL, Bernadete - Brincando com musica na sala de aula: jogos de criação musical usando a voz, o corpo e o movimento: Bernadete Zagonel. São Paulo: Saraiva 2012.

Como citar este artigo (Formato ABNT):

PEREIRA, Maria Matilde de B. A Música como Atividade Interatia no Desenvolvimento Crítico E Social da Educação Infantil. Id on Line Revista Multidisciplinar e de Psicologia, 2017, vol.11, n.38, p. 419-430. ISSN: 1981-1179.

Recebido: 30.10 .2017

Aceito: 01.11.2017 